\title{
Baseline metals pollution profile of tropical estuaries and coastal waters of the Straits of Malacca
}

\begin{abstract}
The status report on metal pollution in tropical estuaries and coastal waters is important to understand potential environmental health hazards. Detailed baseline measurements were made on physicochemical parameters $(\mathrm{pH}$, temperature, redox potential, electrical conductivity, salinity, dissolved oxygen, total dissolved solid), major ions ( $\mathrm{Na}, \mathrm{Ca}, \mathrm{Mg}, \mathrm{K}$, $\mathrm{HCO} 3, \mathrm{Cl}, \mathrm{SO} 4$ and $\mathrm{NO} 3$ ) and metals concentrations (27Al, 75As, 138Ba, 9Be, 111Cd, $59 \mathrm{Co}, 63 \mathrm{Cu}, 52 \mathrm{Cr}, 57 \mathrm{Fe}, 55 \mathrm{Mn}, 60 \mathrm{Ni}, 208 \mathrm{~Pb}, 80 \mathrm{Se}, 66 \mathrm{Zn})$ at estuaries and coastal waters along the Straits of Malacca. Principal component analysis (PCA) was employed to reveal potential pollution sources. Seven principal components were extracted with relation to pollution contribution from minerals-related parameters, natural and anthropogenic sources. The output from this study will generate a profound understanding on the metal pollution status and pollution risk of the estuaries and coastal system.
\end{abstract}

Keyword: Baseline; Estuaries; Coastal waters; Metals; Pollution status; Pollution sources 